\title{
Understanding Student's Learning \& e-Learning Style Before University Enrollment: A Case Study in Five High Schools / Sulaimani-KRG
}

\author{
Mazen Ismaeel Ghareb \\ Computer Science Dept. \\ College of Science and Technology \\ University of Human Development, \\ Sulaimani,Iraq \\ mazen.ismaeel@uhd.edu.iq
}

\author{
Sazgar Hamameen Karim \\ School of Humanity Sciences, \\ Media department Public Relations \\ University of Sulaimani \\ Sulaimani, Iraq \\ sazgar.kareem@univsul.edu.iq
}

\author{
Zanyar Ali Ahmed \\ Information Technology Department \\ Technical College of Informatics \\ Sulaimani Polytechnic University \\ Sulaimani, Iraq \\ zanyar.ahmed@spu.edu.iq
}

\author{
Jamal Kakbra \\ Sulaimani Polytechnic University, \\ University of Human Development \\ Sulaimani,Iraq \\ jamal.kakbra@spu.edu.iq
}

\begin{abstract}
In spite of the advantages of e-learning which have been talked about in different past researches; it is a basic issue to better understand the reasons why a few numbers of students have been disappointed with the e-learning background. Along these lines, these examinations of the researches among students are fulfillment, behavioral goals, and the adequacy of the conventional learning framework that KRG utilizes with worldwide using of e-learning system. A total of 500 secondary school students of 11 and 12 grades was surveyed using a standard survey of questionnaires. The outcomes demonstrated that apparent self-viability is a basic factor that impacts students' fulfillment with the e-learning framework and shows how the customary framework has numerous disadvantages. Seen convenience and saw fulfillment both add the student's behavioral expectation to utilize the e-learning framework. Besides, e-learning viability can be affected by multimedia guideline, intuitive learning exercises, and e-learning framework quality. This examination proposes an applied model for student's fulfillment, behavioral aim, and viability of utilizing the e-learning framework before enrolling in the university.
\end{abstract}

Keywords: Education System, e-Learning, Blended learning, course management, students' behaviors and engagement

\section{INTRODUCTION}

Experts in psychology and Sociology fields have divided the types of human personality. One of the useful divisions in the process of learning and education is the division called (Kinesthetic, Visual, and Auditory).

In this paper, we stepped to define the percentage of all the three types of $(\mathrm{K}, \mathrm{V}, \mathrm{A})$ to find out the students' personality according to each type which is the equivalent personality of student to get higher quality and less cost. This study surveyed 500 students, 475 answers have been received from five high schools in Sulaimani city. It so reaches (of minimum ability and farthest product) as well as studying qualitative of personality.

Educating and learning through on the web. Training industry encountered a changeover from customary face to face classes either full time or through separation instruction to a handheld smaller circle with advantage of constant course. The development of elearning is considerably higher in creating nations when contrasted and creating countries.

E-learning has developed towards the length and width of the globe as the public medium of teaching for both training and education objective. The educational manufacture as fully as many strategies make a material development in the technology qualify learning Elearning systems [2]. Learners and understudies may see great instructing and normal for good educators in an unexpected way. A few scientists have investigated educators' impression of good instructing and great educators while others have analyzed understudies' recognitions [3]. To beat this issue, the utilization of data advances, for example, the web with PCs, PDAs and cell phone applications in checking school exercises and systems administration among school groups has been expanded [4] [5].

\section{LITERATURE REVIEW}

As of now a lot of research has been conducted on student's learning style, e-learning definition, engagement and benefits of e-learning but the following are most relevant to this paper:

\subsection{Definitions of e-Learning}

A comparative analysis of traditional education system vs. E-learning:

According to this [1] E-Learning term is defined as, "innovative approach to education delivery via electronic forms of information that enhance the students' skills, knowledge, or other learning performance". Other scholars define the term E-learning as "the usage of new and modern Information and Communications Technology (ICT) with the help of networks of computers to provide learning materials, teaching, and information to stakeholder".[4] .

Another definition is from this paper a study on the relationship between demographic factor and e-learning readiness among students in higher education "The way of communication and learning through electronic medium is known as e-learning or online learning." [2]

\subsection{Learning Style}

Students can learn in different style. A learning style is the way in which a learner acquires information. Four learning styles have been defined. These are: 
- Activists learn by doing and experiences

- Theorists like to understand the theory behind their actions

- Reflectors learn by observing and thinking about what has happened

- Pragmatists need to be able to see how to put their learning into practice in the real world .[11]

"Learning problems are frequently not related to the difficulty of the subject matter but are associated with the type and level of cognitive process required to learn the material."'[10]

To be a successful person in this knowledge based society, it is important to improve the ability of learning. According to Bloom's taxonomy, there are three domains of learning, i.e. cognitive domain, affective domain and psychomotor domain.

The cognitive domain involves the development of mental skills and the acquisition of knowledge. Thinking is the main part of this category, such as knowledge, comprehension, application, analysis, synthesis and evaluation. Affective domain includes feelings, emotions, attitudes, values, and motivations. Psychomotor domain includes physical movement, coordination, motor and sensory-skills. [9]

\subsection{Benefits of e-Learning}

E-learning has a lot of benefits which of them have been discussed in many articles some of them are:

- E-Learning reaches geographically across and capable of spreading knowledge to remote areas.

- Cost of education is reduced

- E-Learning aimed in flexibility, scalability and rapid deploy ability of web based learning, promoting innovation."'[6]

- "Effective interaction among Students and Instructors.

- Easy Accessibility of Information.’[5]

- Freedom to express thoughts, and ask questions, without limitations.

- The accessibility to the course online materials at the students' own election.[12]

\subsection{Current Status and Development of $e$ - Learning in $K R G$}

ICT Development in Kurdistan Region Kurdistan is in its preliminary stages. Current statistics show that IT is one of the world's largest industries. In 2002, worldwide IT spending reached US\$1 Trillion and the projected growth rate was about $9.4 \%$ from the period from 2001 to 2006. Most countries whether they are developed or developing, rich or poor, small or large appear to spend between $1 \%$ to $3 \%$ of their total budget on ICT. The Kurdistan region spends $0.02 \%$, which is not a healthy situation and is not in line with global trends and best practices. At this percentage Kurdistan Region will fall behind if the budget for ICT does not reach at $1.00 \%$ at least, at this, Kurdistan Region has to increase this percentage to target it.[7]

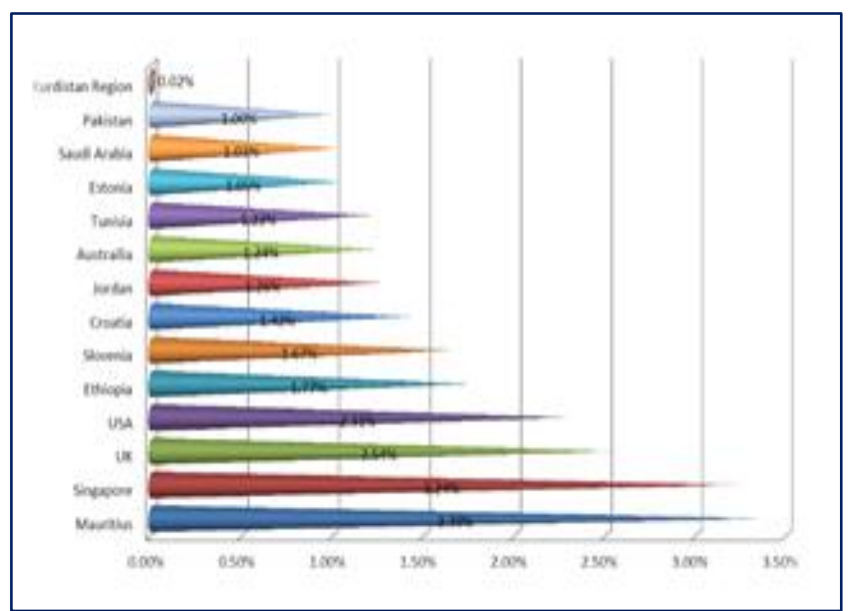

Figure.1 IT spending as percentage of the Total Government Budget

\section{METHODS AND MATERIALS}

In this research, an investigation on the learning styles among high school students have been performed. It has been analyzed the three types of learning styles: Auditory Learners, Visual Learners and Kinesthetic Learners $(\mathrm{A}, \mathrm{V}, \mathrm{K})[1]$. This study surveyed among 500 students and 475 answers have been received from five high schools in Suliamani city. The main aim of this work is to identify the student's style of learning. Another point is to distinguish the student's learning style in order to improve the quality of learning. Adding more this study helps to propose a new education system includes e-learning materials and techniques. This study also helps in reducing the current system extra cost of finding the drawbacks of the current educational system. The goal is also to generalize the study to all other students in KRG in all the cities. The survey was composed of 13 questions: the first 3 questions were about general information about the students, the other 10 questions concerned of learning style for students and the categories for each style of learning (A, V, K).

The survey have been divided into three categories as shown in Table1

Table 1 Survey learning style categories

\begin{tabular}{|l|c|c|c|c|}
\hline \multicolumn{2}{|l|}{ Question Number } & $\begin{array}{l}\text { Auditory } \\
\text { Learners } \\
\text { Answers }\end{array}$ & $\begin{array}{l}\text { Visual } \\
\text { Learners } \\
\text { Answers }\end{array}$ & $\begin{array}{l}\text { Kinesthetic } \\
\text { Learners } \\
\text { Answers }\end{array}$ \\
\hline 1 & Answer & 1 & 2 & 3 \\
\hline 2 & Answer & 2 & 1 & 3 \\
\hline 3 & Answer & 1 & 2 & 3 \\
\hline 4 & Answer & 1 & 2 & 3 \\
\hline
\end{tabular}




\begin{tabular}{|l|l|l|l|l|}
\hline 5 & Answer & 2 & 1 & 3 \\
\hline 6 & Answer & 2 & 1 & 3 \\
\hline 7 & Answer & 1 & 2 & 3 \\
\hline 8 & Answer & 1 & 2 & 3 \\
\hline 9 & Answer & 3 & 1 & 2 \\
\hline 10 & Answer & 3 & 2 & 1 \\
\hline
\end{tabular}

\section{RESULTS}

The first questions of the survey show the age range for the students as it appears in table2.

Table 2 Age Information

\begin{tabular}{|c|c|c|}
\hline Student No. & Age & Percentages \\
\hline 372 & 17 & $78 \%$ \\
\hline 71 & 18 & $15 \%$ \\
\hline 32 & 19 & $7 \%$ \\
\hline Total & & $100 \%$ \\
\hline
\end{tabular}

The results show that most of students complete their levels of study in 17 years which means that they complete successfully in time, while the $7 \%$ shows that their stage will be delayed due to one year failure. These results give a start that most of the students can pass in all the stages.

The second question is gender; however three high schools of girls and two high schools of boys have been surveyed that makes the number of female be higher than males. As it appears in table 3

Table 3 Gender Percentage

\begin{tabular}{|l|l|l|l|}
\hline \multicolumn{2}{|l|}{ Students No. } & Gender & Percentage \\
\hline \multicolumn{2}{|c|}{184} & Male & $39 \%$ \\
\hline \multicolumn{2}{|c|}{291} & Female & $61 \%$ \\
\hline Total & 475 & & $100 \%$ \\
\hline
\end{tabular}

The third question is about the high school study branch whether scientific or literary in. The result shows that $66 \%$ are scientific and $34 \%$ are literary branch. Table 3 shows the percentages of students distributions.

Table 4 Study Branch

\begin{tabular}{|c|c|c|}
\hline Students No. & Study Branch & Percentages \\
\hline 314 & Scientific & $66 \%$ \\
\hline 161 & Literary & $34 \%$ \\
\hline Total & & $100 \%$ \\
\hline
\end{tabular}

The above table shows that most of the students in these schools prefer scientific study branch not a literary one.

Students' comprehension of the subjects, the question was if the teacher explains the subject for the first time; what he would like to start with. Fig1. Explain the students' answers.

\section{Students Comprehension}

Teacher explian the subject oraly.

Teacher explian the subject by graphical methods.

Teacher explian the subject by real example practicaly if possible.

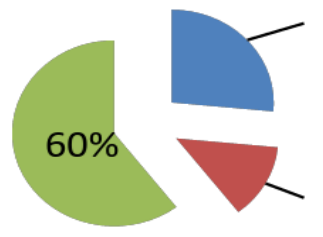

$27 \%$

$13 \%$

Figure 2 Student's Comprehension about the subjects

It is obvious from the results that $60 \%$ of the students prefer to start a lecture with practical example or real example for any subject.

Question 5 is about student's way of seating while studying. As it appears in Figure 3.

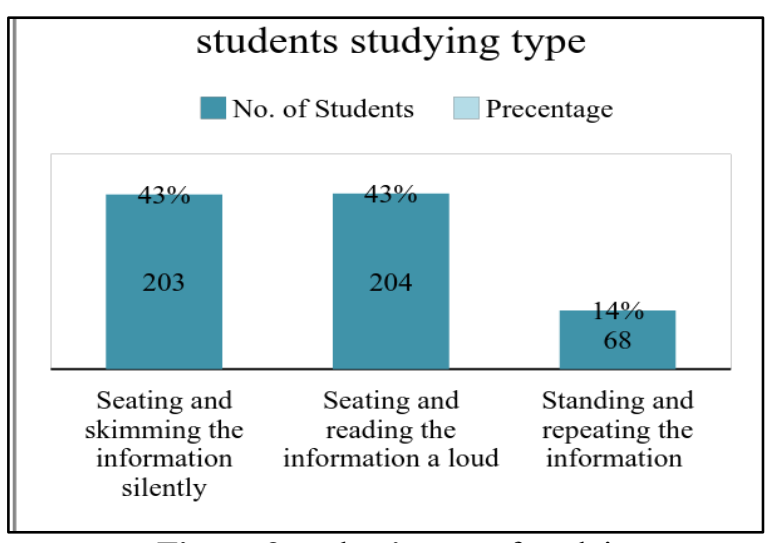

Figure 3 student's way of studying

The results show that the common study type of the students is reading information and repeating it, this concludes that students have to be learnt the methods for reading regarding the subject. Question six is dealing with the factors that affecting student's focus and understanding in learning process. Figure 4 shows the answers of the students.

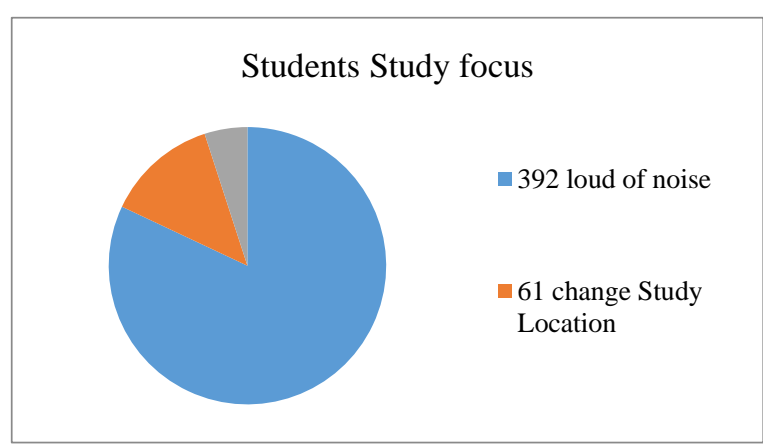

Figure 4 Student's focus in the learning process 
The results show that the main factors that leads to students distraction in the classroom is highly noisiness so, this factor have to be eliminated in order to achieve good quality of the learning process. Question number seven is about students' activities in their free times. The results show in Figure 5.

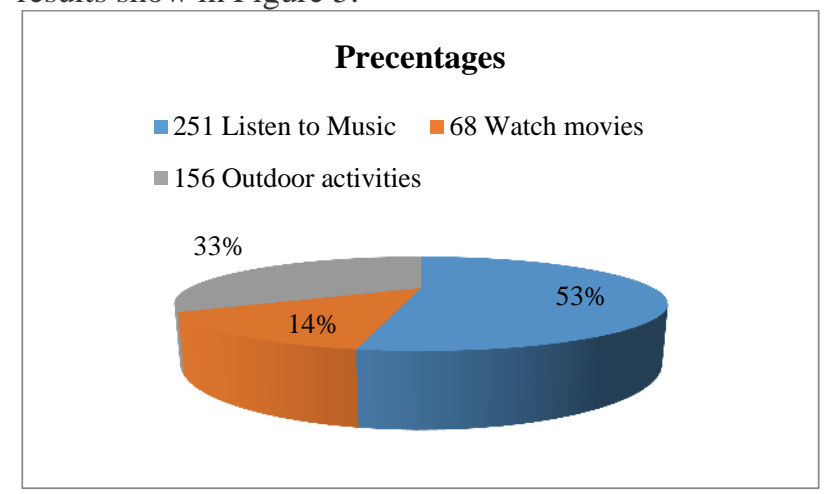

Figure 5 Students Free Times Activities

The results show that the majority of the students will enjoy their free times by listening to music which helps teachers to focus on auditory materials that helps students as well to consider on the subjects, while $33 \%$ of students like outdoor activity which also encourages the teachers to have some extra teaching outside the class.

Question 8 concerns with the class environments. Figure.6 illustrates the results.

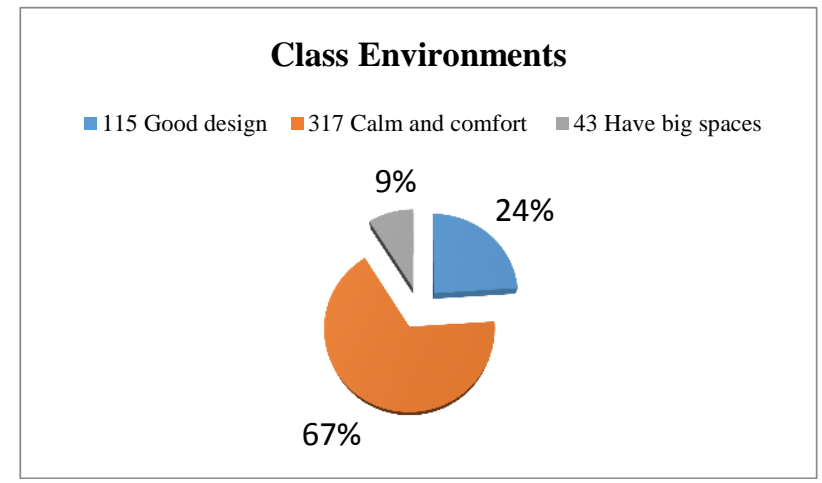

Figure 6 Class Environment

The results show that $67 \%$ of the students prefer a calm class over good design and big space that have $24 \%$ and 9\% percentage, however, it is mixed between good design and calm class that will get a very suitable environment for learning.

The answers of question 9 in the survey ,focuses on teacher's attitude or behavior in the class. Figure 6 explains the result. The data show that $52 \%$ of the students prefer clear voice over the tidiness which is $34 \%$ of the teacher. This is an important factor that the teacher should have a clear voice as a basic characteristic of the lecture than other professionals.

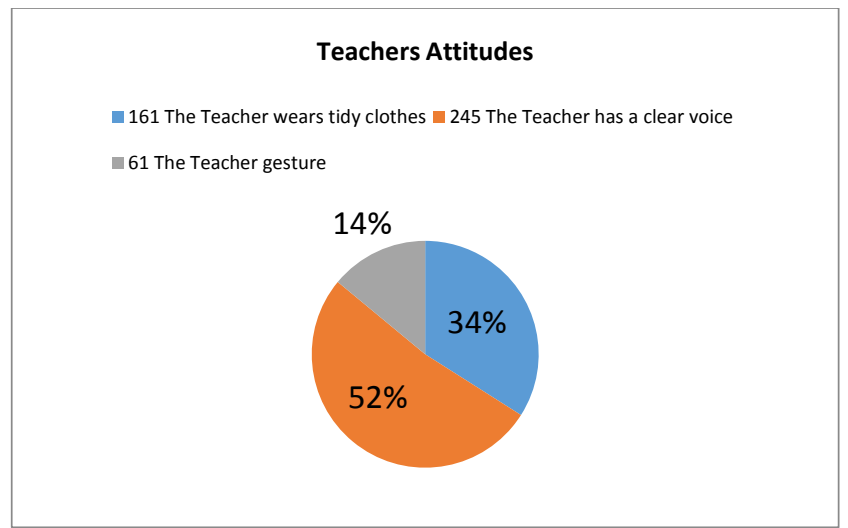

Figure.7 Teacher's attitude or behavior in class

Question 10 is about the teacher who awards, activities in class to the students. In Kurdistan Region, there are many methods that in general the people get used to it. Figure 8 shows the results.

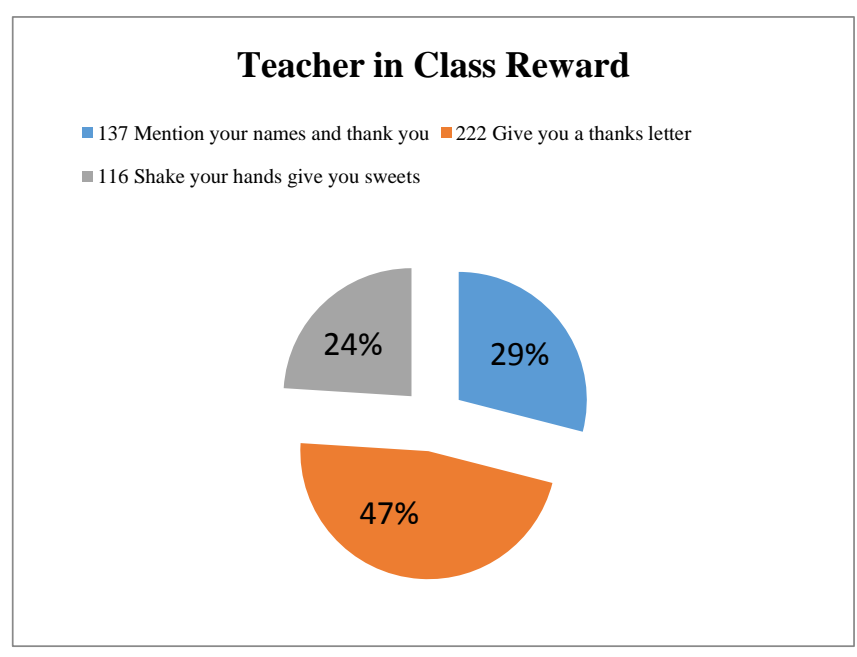

Figure 8 Teacher's Reward in Class

Figure 7 gives the student's thankfulness letter which will improve the lecturing process and encourage the students as shown that the percentage is 47 .

While mentioning his/her name, giving them sweets will be more likely by the students, so it is recommend for the teacher to use different methods and make it as certificate seems better.

Question 11 is dealing with remembering techniques for the knowledge. There are many techniques but the results show only these three which used by the students. Figure. 9 illustrates the results. 


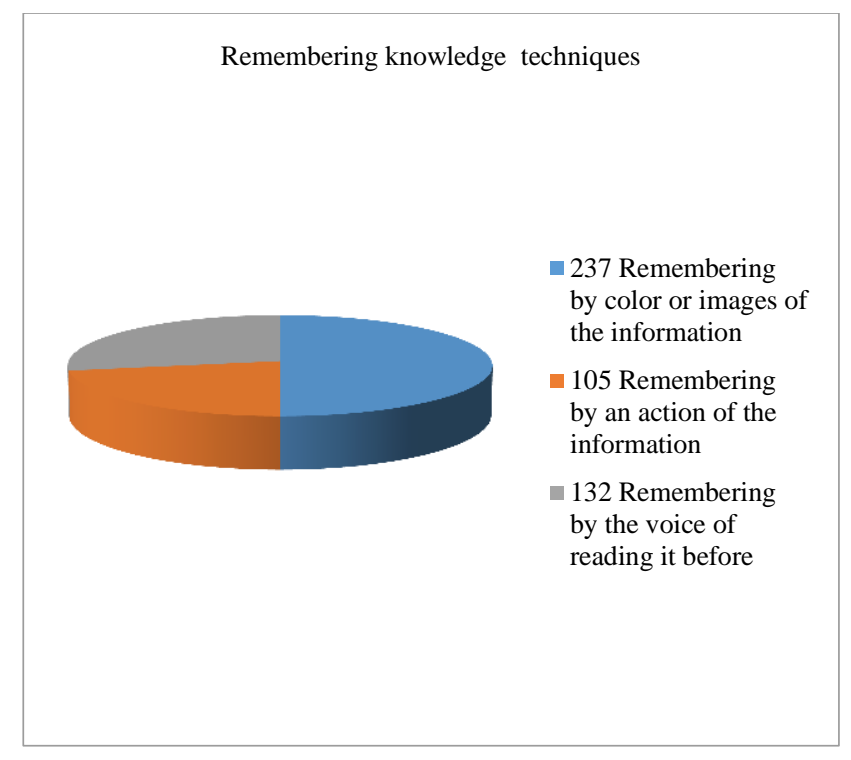

Figure 9 Remembering Technique

The result shows that $50 \%$ of students can remember the information by photo or color text. The other results focus on voice of reading and action on the information which is $28 \%$ and $22 \%$ respectively. This means that the teacher should always use new techniques for helping students to retrieve the information. Nowadays there are many online tools helping teachers to use them in this manner.

Question 12 deals with teacher punishment in class in order to control it. Figure 10 illustrates the results.

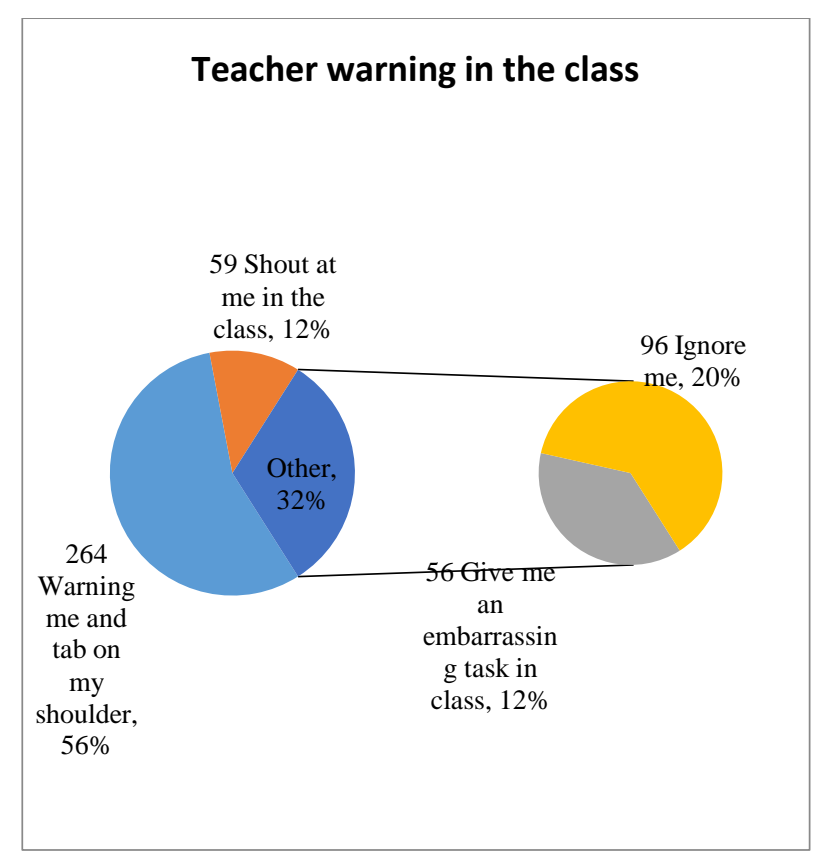

Figure 10 Teacher warning in class

The Results show $56 \%$ would like to be warned in class before further action. While $20 \%$ likes to be ignored and other $12 \%$ prefers shouting and giving embarrassing tasks respectively. This means that the personality of the students would like still to have a physical contact even in punishments. Because these students may need more explanation or more attention so, the teacher should take care of these situations as well

According to the Table1: The results are distributed in three categories. So Figure.11 explains that most of the students are auditory learners, $43 \%$ following with the Visual learners and 30\%, then kinesthetic learners $27 \%$ for a total of 475 students. To conclude: the ministry of education has to think about new techniques in elearning that will help to accomplish these tasks to the best learning styles.

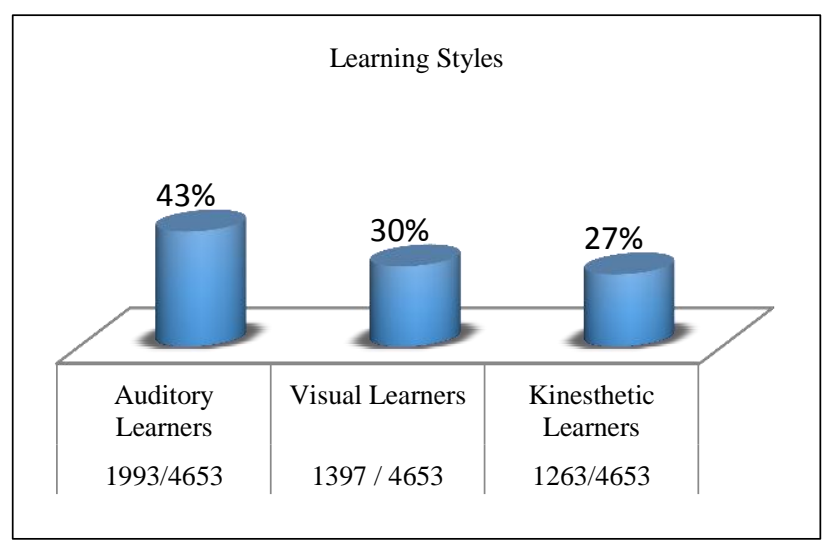

Figure.11 Students Learning Style

\section{DISCUSSION}

Methodology results that students in high schools are not convenient to be learned in a traditional way, they are really in need of a new system of e-learning and intuitive experiences to improve and fulfil quality of education through self-viability as well as teachers needs training with the e-learning systems. We have specific features and the formative-evaluation pilot study of a multirepresentational of how teacher act in classroom of 475 students in 5 different schools.

It has been conducted survey and literature review show that the new education system for the students and teachers will be more effective, less costing and better in quality of learning. The drawbacks of the current education system have as well been found out through the last results of the K.V.A. percentages.

\section{CONCLUSION}

This paper concerns the evaluation of learning style with student's behavior in current situation in 5 high schools as a case study. The chosen schools depends on the level of the students according the ministry of education, they divided between high, medium and law level of students. The study shows that the behavior of the students are vary to regarding auditory style. The lecturer is recommended to have training of how to control the voices of different situations using technological audio tools for subjects such as mobile, laptop and recorders. According to visual learning styles, the lecturer has to research about new way of visually interact with the 
students with many multimedia techniques, for instance making posters with PowerPoint, data shows, color images or short movies and so on.

Finally regarding the kinesthetic style of learning, the lecturer has to have a good training of gesture control according to the subject. In addition, changing the classroom environment and making more outdoors, activity regarding the subject are necessary. Also it is necessary to change the style of the classroom design as much as possible. It is clear that obstacles are there to apply these methods ideally but if each lecturer has a minimum understanding of these technological simple methods, it leads to a big change in student's education in couple of years.

Future plan includes the introduction of new e-learning system of the ministry of education in KRG. A strategic plan for 5 years to partially transform to new online system for students in KRG will be proposed.

\section{REFERENCE}

[1] H. Pashler, M. Mcdaniel, D. Rohrer, and R. Bjork, "Learning Styles," Psychological Science in the Public Interest, vol. 9, no. 3, pp. 105-119, 2008.

[2] K. D. Bruin, "The relationship between personality traits and self-directed learning readiness in higher education students," South African Journal of Higher Education, vol. 21, no. 2, 2007.

[3] F. N.-A. Alhija, "Teaching in higher education: Good teaching through students' lens," Studies in Educational Evaluation, vol. 54, pp. 4-12, 2017.

[4] Y. P. Chua and Y. P. Chua, "How are e-leadership practices in implementing a school virtual learning environment enhanced? A grounded model study," Computers \& Education, vol. 109, pp. 109-121, 2017.

[5] M. I. Ghareb and S. A. M. Mohammed, "The Role Of ELearning In Producing Independent Students With Critical Thinking," International Journal Of Engineering And Computer Science, Mar. 2016.

[6] R. S. Gowda and V. Suma, "A comparative analysis of traditional education system vs. e-Learning," 2017 International Conference on Innovative Mechanisms for Industry Applications (ICIMIA), 2017.

[7] J. F. Kakbra and H. M. Sidiq, "Measuring the impact of ICT and e-learning on higher education system with redesigning and adapting MOODLE system in Kurdistan Region Government, KRG-Iraq," Proceedings of the 2nd e-learning Regional Conference, At State of Kuwait, Volume: 1, vol. 1, 213ADAD.

[8] K. D. Bruin, "The relationship between personality traits and self-directed learning readiness in higher education students," South African Journal of Higher Education, vol. 21, no. 2, 2007.

[9] U. Jayasinghe, A. Dharmaratne, and A. Atukorale, "Students performance evaluation in online education system Vs traditional education system," Proceedings of 2015 12th International Conference on Remote Engineering and Virtual Instrumentation (REV), 2015

[10] J. C. Tseng, H.-C. Chu, G.-J. Hwang, and C.-C. Tsai, "Development of an adaptive learning system with two sources of personalization information," Computers \& Education, vol. 51, no. 2, pp. 776-786, 2008

[11] J. J. Vinales, "The learning environment and learning styles: a guide for mentors," British Journal of Nursing, vol. 24, no. 8, pp. 454-457, 2015.

[12] S.-S. Liaw, "Investigating students' perceived satisfaction, behavioral intention, and effectiveness of e-learning: A case study of the Blackboard system," Computers \& Education, vol. 51 , no. 2, pp. 864-873, 2008 .

\section{ACKNOWLEDGEMENT}

Special thanks to the 5 high schools in Sulaimani,KRG for their supporting in this study. We would like to thank as well the University of Human Development for making the connection with headmasters of the high schools (Roshnber, Safin, Rezheen, Razaw and Sulaimani). 